\title{
Autism Spectrum Disorders: Is Mesenchymal Stem Cell Personalized Therapy the Future?
}

\author{
Dario Siniscalco, ${ }^{1,2}$ Anna Sapone, ${ }^{3,4}$ Alessandra Cirillo, ${ }^{5}$ Catia Giordano, ${ }^{1}$ \\ Sabatino Maione, ${ }^{1}$ and Nicola Antonucci ${ }^{6}$ \\ ${ }^{1}$ Division of Pharmacology "L. Donatelli", Department of Experimental Medicine, Second University of Naples, \\ Via S. Maria di Costantinopoli, 16-80138 Napoli, Italy \\ ${ }^{2}$ Centre for Autism, La Forza del Silenzio, Caserta, 80138 Naples, Italy \\ ${ }^{3}$ Department of Internal and Experimental Medicine "Magrassi-Lanzara", Second University of Naples, 80138 Naples, Italy \\ ${ }^{4}$ Center for Celiac Research and Mucosal Biology Research Center, University of Maryland School of Medicine, Baltimore, \\ MD 21201, USA \\ ${ }^{5}$ Division of Biotechnology and Molecular Biology "A. Cascino", Department of Experimental Medicine, Second University of Naples, \\ 80138 Naples, Italy \\ ${ }^{6}$ Biomedical Centre for Autism Research and Treatment, 70122 Bari, Italy
}

Correspondence should be addressed to Dario Siniscalco, dariosin@uab.edu

Received 11 July 2011; Accepted 29 September 2011

Academic Editor: Ken-ichi Isobe

Copyright ( $) 2012$ Dario Siniscalco et al. This is an open access article distributed under the Creative Commons Attribution License, which permits unrestricted use, distribution, and reproduction in any medium, provided the original work is properly cited.

\begin{abstract}
Autism and autism spectrum disorders (ASDs) are heterogeneous neurodevelopmental disorders. They are enigmatic conditions that have their origins in the interaction of genes and environmental factors. ASDs are characterized by dysfunctions in social interaction and communication skills, in addition to repetitive and stereotypic verbal and nonverbal behaviours. Immune dysfunction has been confirmed with autistic children. There are no defined mechanisms of pathogenesis or curative therapy presently available. Indeed, ASDs are still untreatable. Available treatments for autism can be divided into behavioural, nutritional, and medical approaches, although no defined standard approach exists. Nowadays, stem cell therapy represents the great promise for the future of molecular medicine. Among the stem cell population, mesenchymal stem cells (MSCs) show probably best potential good results in medical research. Due to the particular immune and neural dysregulation observed in ASDs, mesenchymal stem cell transplantation could offer a unique tool to provide better resolution for this disease.
\end{abstract}

\section{Autism Spectrum Disorders}

Autism and autism spectrum disorders (ASDs) are heterogeneous neurodevelopmental disorders [1]. They are enigmatic conditions that have their origins in the interaction of genes and environmental factors. ASDs are characterized by dysfunctions in social interaction and communication skills, in addition to repetitive and stereotypic verbal and nonverbal behaviours $[2,3]$. Several biochemical events are associated with ASDs: oxidative stress; endoplasmic reticulum stress; decreased methylation capacity; limited production of glutathione; mitochondrial dysfunction; intestinal dysbiosis; increased toxic metal burden; immune dysregulation; immune activation of neuroglial cells [4]. The exact aetiology of ASDs is unknown, likely it results from a complex combination of genetic, environmental, and immunological factors $[5,6]$. This heritable disorder derives from genetic variations in multiple genes [7], making its treatment particularly difficult. Environment (i.e., air pollution, organophosphates, and heavy metals) also contributes to the incidence of ASDs [8].

Frequency of these disorders is increasing: $56 \%$ reported increase in paediatric prevalence between 1991 and 1997 [9] until present rates of about 60 cases per 10,000 children, according to Center for Disease Control $[10,11]$. ASDs are increasingly being recognized as a public health problem [12]. Pathophysiology and defined mechanisms of pathogenesis of autism remain still unclear. There are no 
drugs effective for treatment of core symptoms of ASDs [10]. Indeed, ASDs are still untreatable. Current available treatments for autism can be divided into behavioural, nutritional, and pharmacological options, in addition to individual and family psychotherapy and other nonpharmacologic interventions [13]. However, no defined standard approach exists [14]. Pharmacological approaches are direct towards neuropsychiatric disorders coassociated with ASDs. Psycho-stimulants, alpha-2 agonists, beta blockers, lithium, anticonvulsant mood stabilizers, atypical antipsychotics, traditional antipsychotics, selective serotonin reuptake inhibitors, antidepressants, and antipsychotics, are drugs commonly prescribed [14-16]. Catatonia is treated with lorazepam and bilateral electroconvulsive therapy [17]. Selective serotonin reuptake inhibitors are prescribed for the treatment of depression, anxiety, and obsessive-compulsive ASD-associated behaviours [2].

Other nonpsychotropic drugs which are supported by at least 1 or 2 prospective randomized controlled trials or 1 systematic review include melatonin, acetylcholinesterase inhibitors, naltrexone, carnitine, tetrahydrobiopterin, vitamin C, hyperbaric oxygen treatment, immunomodulation and anti-inflammatory treatments, oxytocin, and even music therapy and vision therapy [18].

Alternative and complementary treatments, not sufficiently supported by medical literature, include herbal remedies, vitamin and mineral therapies, piracetam, elimination diets, chelation, cyproheptadine, famotidine, glutamate antagonists, special dietary supplements, acupuncture, neurofeedback, and sensory integration training $[14,19,20]$. On the other hand, behavioural treatment could represent the effective intervention strategy for autism [21-23]. A plethora of behavioural strategies and social skill trainings have been used [24-26]. However, it has been demonstrated that no definitive behavioural intervention completely improves all symptoms for all ASD patients $[27,28]$.

Summarizing, all these therapies indicate that further research is needed to better address treatment of several medical conditions experienced by ASD patients [29].

\section{Mesenchymal Stem Cells}

Nowadays, stem cell therapy represents the great promise for the future of molecular medicine. The progression of several diseases can be slowed or even blocked by stem cell transplantation [30].

Among the stem cell population, mesenchymal stem cells (MSCs) show probably best potential good results in medical research [31-33]. These cells are nonhematopoietic stem cells having a multilineage potential, as they have the capacity of differentiating into both mesenchymal and nonmesenchymal lineages. MSCs are a population of progenitor cells of mesodermal origin found principally in the bone marrow of adults, giving rise to skeletal muscle cells, blood, fat, vascular, and urogenital systems, and to connective tissues throughout the body [34-36]. According to the International Society of Cellular Therapy, MSCs are defined by the following minimal set of criteria: (1) grown in adherence to plastic surface of dishes when maintained in standard culture conditions; (2) express cytospecific cell surface markers, that is, CD105, CD90, and CD73, to be negative for other cell surface markers, that is, CD45, CD34, CD14, and CD11b; (3) possess the capacity to differentiate into mesenchymal lineages, under appropriate in vitro conditions [37]. MSCs can be isolated from different tissues other than bone marrow: adipose tissue, liver, tendons, synovial membrane, amniotic fluid, placenta, umbilical cord, and teeth. MSCs show a high expansion potential, genetic stability, stable phenotype, high proliferation rate as adherent cells, and self-renew capacity and can be easily collected and shipped from the laboratory to the bedside and are compatible with different delivery methods and formulations $[38,39]$. In addition, MSCs have two other extraordinary properties: they are able to migrate to sites of tissue injury, where they are able to inhibit the release of proinflammatory cytokines and have strong immunosuppressive activity that renders them a useful tool for successful autologous, as well as heterologous, transplantations without requiring pharmacological immunosuppression [40-43]. Besides, MSCs are easily isolated from a small aspirate of bone marrow and expanded with high efficiency [44]. Given that MSCs are multipotent cells with a number of potential therapeutic applications, and they represent a future powerful tool in regenerative medicine, including ASDs. Mesenchymal stem cells could be transplanted directly without genetic modification or pretreatments. They simply eventually differentiate according to cues from the surrounding tissues and do not give uncontrollable growth or tumours. In clinical application, there is no problem with immune rejection because of their in vivo immunosuppressive properties [45, 46]. In addition, MSCs can readily be isolated from the patients requiring transplant or from their parents. There is also no tumour formation on transplantation [47]. No moral objection or ethical controversies are involved [48].

In principle, mesenchymal stem cells can act through several possible mechanisms, that is, stimulating the plastic response in the host damaged tissue, secreting survivalpromoting growth factors, restoring synaptic transmitter release by providing local reinnervations, integrating into existing neural and synaptic network, and reestablishing functional afferent and efferent connections [49]. Since MSCs have the capability to produce a large array of trophic and growth factors both in vivo and in vitro. (MSCs constitutively secrete interleukins (IL)-6, IL-7, IL-8, IL-11, IL-12, IL-14, IL-15, macrophage colony-stimulating factor, Flt-3 ligand, and stem-cell factor [50]). A more reasonable explanation for the functional benefit derived from MSC transplantation is their paracrine activity, by which these cells are able to produce factors that activate endogenous restorative mechanisms within injured tissues contributing to recovery of function lost as a result of lesions $[49,51]$.

\section{Autism, Personalized Therapy through Mesenchymal Stem Cells}

MSCs have a strong long-lasting immunosuppressive capacity [52]. This extraordinary property is mediated via soluble 


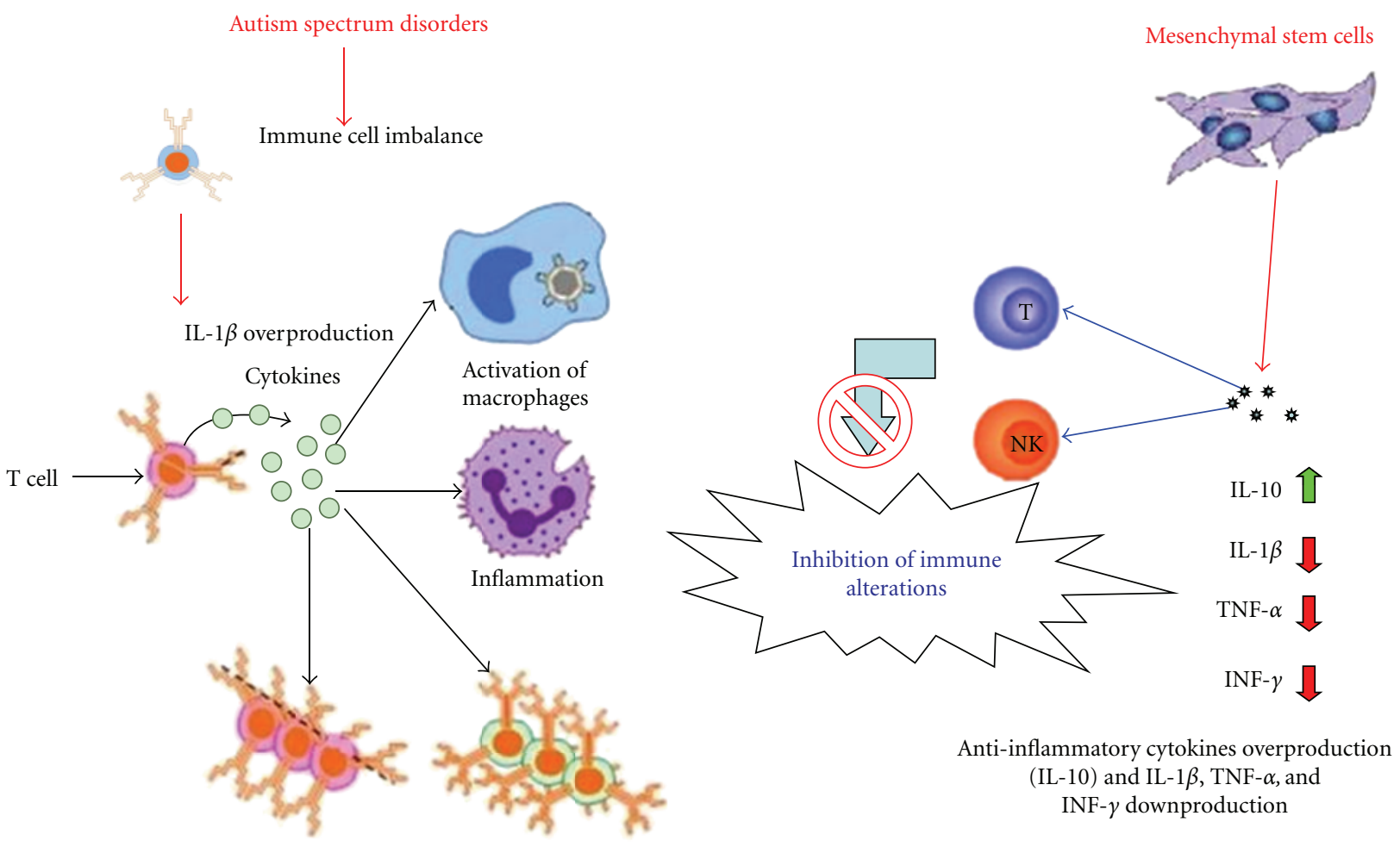

Activation of $\mathrm{T}$ and B lymphocytes

FIGURE 1: Paracrine and immunomodulatory effects as possible mechanisms of action of mesenchymal stem cells (MSCs) in autism spectrum disorder (ASD) treatment. In humans, ASDs are associated with immune alterations and pro-inflammatory cytokines (i.e., IL-1 $\beta$ ) overproduction. These cytokines are able to trigger pro-inflammatory cellular events. Data from in vitro models show that MSCs are able to affect not only T cells, but also other cells of the immune system (i.e., NK cells). Immunoregulatory properties of MSCs are through secretion of large amounts of several bioactive molecules (paracrine activity), that is, PGE-2, IL-10. These molecules cause the inhibition or the unresponsiveness of T-cell mediated responses.

factors. MSCs are able to inhibit the proliferation of $\mathrm{CD}^{+}$ and $\mathrm{CD}^{+} \mathrm{T}$ lymphocytes and natural killer $(\mathrm{NK})$ cells, to suppress the immunoglobulin production by plasma cells, to inhibit the maturation of dendritic cells (DCs) and the proliferation of regulatory $T$ cells [53]. It has been demonstrated that MSCs are also able to inhibit T lymphocyte pro-inflammatory cytokine production in vitro $[54,55]$, as well as in vivo [56]. Their ability to modulate the immune system opens a wide range of cell-mediated applications, not only for autoimmune diseases and graftversus-host disease. Due to the particular immune system dysregulation observed in ASDs [57, 58], mesenchymal stem cell transplantation could offer a unique tool to provide better resolution for this disease. Indeed, in ASDs pathogenesis, innate and adaptive immunity changes have been reported [59]. ASD patients show an imbalance in $\mathrm{CD}^{+}$, $\mathrm{CD}^{+}$, and $\mathrm{CD}^{+} \mathrm{T}$ cells, as well as in NK cells. In addition, peripheral blood mononuclear cells (PBMCs) extracted from ASD patients are able to overproduce IL- $1 \beta$ resulting in long-term immune alterations [60]. MSC-mediated immune suppressive activity could restore this immune imbalance (Figure 1). Indeed, MSC immunoregulatory effects strongly inhibit T-cell recognition and expansion by inhibiting TNF- $\alpha$ and INF- $\gamma$ production and increasing IL-10 levels [51].
It has been demonstrated that in postmortem brains from ASD patients there is evidence of abnormal functioning and cerebellum alterations [61-63]. Indeed, ASD subjects show a decreased number of Purkinje cells in the cerebellum [64]. These changes could reflect defective cortical organization in ASDs development. In addition, autism is associated with dysregulation in the maturation and plasticity of dendritic spine morphology [65]. Restoring injured brain functioning could be achieved by stem-cell-based cell replacement [66]. Indeed, transplanted MSCs are able to promote synaptic plasticity and functional recovery and rescue cerebellar Purkinje cells $[67,68]$. Challenging newest study from Deng et al. suggests that granulocyte colonystimulating factor (G-CSF) is able to mobilize MSCs into peripheral blood. These mobilized MSCs are incorporated and integrate into damaged brain in craniocerebral injured mice, ameliorating the effect of trauma [69]. It is noteworthy that MSC ability to migrate to the sites of injury and participate in the repair process is a key issue in tissue repair [70]. Also by this way, MSC therapy could restore the altered brain organization seen in autistic subjects (Table 1).

A key dilemma in stem-cell-based therapy for autism treatment is whether endogenous or exogenous MSC administration is the best way of stem cell delivery. Endogenous 
TABle 1: Potential ameliorative effects mediated by MSCs in ASD treatment.

\begin{tabular}{ll}
\hline $\begin{array}{l}\text { ASD-induced changes in human } \\
\text { brain }\end{array}$ & $\begin{array}{l}\text { Potential MSC ameliorative roles } \\
\text { seen in preclinical models }\end{array}$ \\
\hline Abnormal functioning & $\begin{array}{l}\text { Improving functional recovery } \\
\text { Integrating in altered brain and } \\
\text { restoring damaged functions }\end{array}$ \\
Cerebellum alterations & Restoring cerebellar PCs \\
$\begin{array}{l}\text { Decreased number of Purkinje } \\
\text { cells (PCs) }\end{array}$ & Reinforcing cortical plasticity \\
$\begin{array}{l}\text { Defective cortical organization } \\
\text { Altered plasticity of dendritic } \\
\text { spine morphology }\end{array}$ & Promoting synaptic plasticity \\
\hline
\end{tabular}

strategy could be limited by the availability of MSCs. Exogenous MSCs could show low rate of engraftment to provide cellular replacement. It is unclear if differentiated cells are able to develop functional interconnections with the intrinsic cells of the recipient host [49]. Controversy, few exogenous MSCs are able to exert paracrine activity. Indeed, exogenously applied MSCs have been shown to home to injured tissues and repair them by producing chemokines, or by cell or nuclear fusion with host cells [71]. On the other hand, exogenous culture-expanded MSCs could address endogenous MSCs in order to activate them and guide intrinsic repair [72]. In addition, exogenous delivery bypasses surgical intervention on the autistic child.

Cellular therapy could represent a new frontier in the treatment of several diseases. Despite the fact that MSCs have been enrolled in several clinical trials, long-term safety of MSC-based therapies is not yet well established; this fact could be one major limitation to clinical translation [73]. At the present, there are no preclinical studies on the use of MSCs in ASD models. There is just one clinical trial (NCT01343511 http://www.clinicaltrial.gov/) concerning the safety and efficacy of human umbilical cord mesenchymal stem cells (hUC-MSCs) and human cord blood mononuclear cells (hCB-MNCs) transplantation in patients with autism by Shenzhen Beike Bio-Technology Co., China. Results are not yet posted.

However, personalized stem cell therapy will be the most effective treatment for a specific autistic child, opening a new era in autism management in the next future.

\section{Acknowledgments}

The authors gratefully thank Mr. Enzo Abate, Ms. Giovanna Gallone, and the nonprofit organizations "La Forza del Silenzio" and "Cancellautismo," Italy for their useful assistance. The authors thank the Autism Research Institute, USA (ARI grant "Research that makes a difference" 2010) for financial support of this study.

\section{References}

[1] A. Fasano, "Intestine, leaky gut, autism and probiotics," in Cutting Edge Therapies, N. J. Lyndhurst, Ed., pp. 192-198, Barnes \& Noble, 2010.
[2] K. Williams, D. M. Wheeler, N. Silove, and P. Hazell, "Selective serotonin reuptake inhibitors (SSRIs) for autism spectrum disorders (ASD)," Cochrane Database of Systematic Reviews, vol. 8, Article ID CD004677, 2010.

[3] R. Toro, M. Konyukh, R. Delorme et al., "Key role for gene dosage and synaptic homeostasis in autism spectrum disorders," Trends in Genetics, vol. 26, no. 8, pp. 363-372, 2010.

[4] J. J. Bradstreet, S. Smith, M. Baral, and D. A. Rossignol, "Biomarker-guided interventions of clinically relevant conditions associated with autism spectrum disorders and attention deficit hyperactivity disorder," Alternative Medicine Review, vol. 15, no. 1, pp. 15-32, 2010.

[5] A. M. Persico and T. Bourgeron, "Searching for ways out of the autism maze: genetic, epigenetic and environmental clues," Trends in Neurosciences, vol. 29, no. 7, pp. 349-358, 2006.

[6] R. Toro, M. Konyukh, R. Delorme et al., "Key role for gene dosage and synaptic homeostasis in autism spectrum disorders," Trends in Genetics, vol. 26, no. 8, pp. 363-372, 2010.

[7] P. El-Fishawy and M. W. State, "The genetics of autism: key issues, recent findings, and clinical implications," Psychiatric Clinics of North America, vol. 33, no. 1, pp. 83-105, 2010.

[8] M. R. Herbert, "Contributions of the environment and environmentally vulnerable physiology to autism spectrum disorders," Current Opinion in Neurology, vol. 23, no. 2, pp. 103-110, 2010.

[9] R. Muhle, S. V. Trentacoste, and I. Rapin, "The genetics of autism," Pediatrics, vol. 113, no. 5, pp. e472-e486, 2004.

[10] S. E. Levy, D. S. Mandell, and R. T. Schultz, "Autism," The Lancet, vol. 374, no. 9701, pp. 1627-1638, 2009.

[11] CDC, "Surveillance summaries," Morbidity and Mortality Weekly Report, vol. 56, pp. 1-28, 2007.

[12] P. A. Main, M. T. Angley, P. Thomas, C. E. O'Doherty, and M. Fenech, "Folate and methionine metabolism in autism: a systematic review," American Journal of Clinical Nutrition, vol. 91, no. 6, pp. 1598-1620, 2010.

[13] A. M. Reiersen and R. D. Todd, "Co-occurrence of ADHD and autism spectrum disorders: phenomenology and treatment," Expert Review of Neurotherapeutics, vol. 8, no. 4, pp. 657-669, 2008.

[14] J. T. McCracken, "Safety issues with drug therapies for autism spectrum disorders," Journal of Clinical Psychiatry, vol. 66, supplement 10, pp. 32-37, 2005.

[15] M. Tandon and J. R. Pruett Jr., "An overview of the use of antidepressants in children and adolescents," Missouri Medicine, vol. 105, no. 1, pp. 79-85, 2008.

[16] R. M. Nevels, E. E. Dehon, K. Alexander, and S. T. Gontkovsky, "Psychopharmacology of aggression in children and adolescents with primary neuropsychiatric disorders: a review of current and potentially promising treatment options," Experimental and Clinical Psychopharmacology, vol. 18, no. 2, pp. 184-201, 2010.

[17] D. M. Dhossche, A. Shah, and L. Wing, "Blueprints for the assessment, treatment, and future study of catatonia in autism spectrum disorders," International Review of Neurobiology, vol. 72, pp. 267-284, 2006.

[18] D. A. Rossignol, "Novel and emerging treatments for autism spectrum disorders: a systematic review," Annals of Clinical Psychiatry, vol. 21, no. 4, pp. 213-236, 2009.

[19] H. G. Şenel, 'Parents' views and experiences about complementary and alternative medicine treatments for their children with autistic spectrum disorder," Journal of Autism and Developmental Disorders, vol. 40, no. 4, pp. 494-503, 2010.

[20] V. C. Wong and J. G. Sun, "Randomized controlled trial of acupuncture versus sham acupuncture in autism spectrum 
disorder," Journal of Alternative and Complementary Medicine, vol. 16, no. 5, pp. 545-553, 2010.

[21] P. A. Filipek, R. Steinberg-Epstein, and T. M. Book, "Intervention for autistic spectrum disorders," NeuroRx, vol. 3, no. 2, pp. 207-216, 2006.

[22] L. A. Vismara and S. J. Rogers, "Behavioral treatments in autism spectrum disorder: what do we know?" Annual Review of Clinical Psychology, vol. 6, pp. 447-468, 2010.

[23] C. Kasari and K. Lawton, "New directions in behavioral treatment of autism spectrum disorders," Current Opinion in Neurology, vol. 23, no. 2, pp. 137-143, 2010.

[24] L. C. Murdock and J. Q. Hobbs, "Picture me playing: increasing pretend play dialogue of children with autism spectrum disorders," Journal of Autism and Developmental Disorders, vol. 41, pp. 870-878, 2011.

[25] F. Frankel and C. Whitham, "Parent-assisted group treatment for friendship problems of children with autism spectrum disorders," Brain Research, vol. 1380, pp. 240-245, 2011.

[26] M. Valenti, R. Cerbo, F. Masedu, M. De Caris, and G. Sorge, "Intensive intervention for children and adolescents with autism in a community setting in Italy: a singlegroup longitudinal study," Child and Adolescent Psychiatry and Mental Health, vol. 4, article no. 23, 2010.

[27] M. B. Ospina, J. K. Seida, B. Clark et al., "Behavioural and developmental interventions for autism spectrum disorder: a clinical systematic review," PLoS One, vol. 3, no. 11, Article ID e3755, 2008.

[28] A. C. Stahmer, L. Schreibman, and A. B. Cunningham, "Toward a technology of treatment individualization for young children with autism spectrum disorders," Brain Research, vol. 1380, pp. 229-239, 2011.

[29] D. Coury, "Medical treatment of autism spectrum disorders," Current Opinion in Neurology, vol. 23, no. 2, pp. 131-136, 2010.

[30] D. Siniscalco, N. Sullo, S. Maione, F. Rossi, and B. D’Agostino, "Stem cell therapy: the great promise in lung disease," Therapeutic Advances in Respiratory Disease, vol. 2, no. 3, pp. 173-177, 2008.

[31] G. Brooke, M. Cook, C. Blair et al., "Therapeutic applications of mesenchymal stromal cells," Seminars in Cell and Developmental Biology, vol. 18, no. 6, pp. 846-858, 2007.

[32] A. Arthur, A. Zannettino, and S. Gronthos, "The therapeutic applications of multipotential mesenchymal/stromal stem cells in skeletal tissue repair," Journal of Cellular Physiology, vol. 218, no. 2, pp. 237-245, 2009.

[33] P. C. Chagastelles, N. B. Nardi, and M. Camassola, "Biology and applications of mesenchymal stem cells," Science Progress, vol. 93, no. 2, pp. 113-127, 2010.

[34] B. Short, N. Brouard, T. Occhiodoro-Scott, A. Ramakrishnan, and P. J. Simmons, "Mesenchymal stem cells," Archives of Medical Research, vol. 34, no. 6, pp. 565-571, 2003.

[35] N. Beyer Nardi and L. da Silva Meirelles, "Mesenchymal stem cells: isolation, in vitro expansion and characterization," Handbook of Experimental Pharmacology, no. 174, pp. 249282, 2006.

[36] S. Sethe, A. Scutt, and A. Stolzing, "Aging of mesenchymal stem cells," Ageing Research Reviews, vol. 5, no. 1, pp. 91-116, 2006.

[37] M. Dominici, K. Le Blanc, I. Mueller et al., "Minimal criteria for defining multipotent mesenchymal stromal cells. The International Society for Cellular Therapy position statement," Cytotherapy, vol. 8, no. 4, pp. 315-317, 2006.

[38] A. Giordano, U. Galderisi, and I. R. Marino, "From the laboratory bench to the patient's bedside: an update on clinical trials with mesenchymal stem cells," Journal of Cellular Physiology, vol. 211, no. 1, pp. 27-35, 2007.

[39] K. L. Pricola, N. Z. Kuhn, H. Haleem-Smith, Y. Song, and R. S. Tuan, "Interleukin-6 maintains bone marrow-derived mesenchymal stem cell stemness by an ERK1/2-dependent mechanism," Journal of Cellular Biochemistry, vol. 108, no. 3, pp. 577-588, 2009.

[40] K. Le Blanc and M. F. Pittenger, "Mesenchymal stem cells: progress toward promise," Cytotherapy, vol. 7, no. 1, pp. 3645, 2005.

[41] K. J. Beggs, A. Lyubimov, J. N. Borneman et al., "Immunologic consequences of multiple, high-dose administration of allogeneic mesenchymal stem cells to baboons," Cell Transplantation, vol. 15, no. 8-9, pp. 711-721, 2006.

[42] A. Uccelli, L. Moretta, and V. Pistoia, "Mesenchymal stem cells in health and disease," Nature Reviews Immunology, vol. 8, no. 9, pp. 726-736, 2008.

[43] C. E. P. Aronin and R. S. Tuan, "Therapeutic potential of the immunomodulatory activities of adult mesenchymal stem cells," Birth Defects Research Part C Embryo Today, vol. 90, no. 1, pp. 67-74, 2010.

[44] D. Siniscalco, "Transplantation of human mesenchymal stem cells in the study of neuropathic pain," Methods in Molecular Biology, vol. 617, pp. 337-345, 2010.

[45] P. A. Sotiropoulou and M. Papamichail, "Immune properties of mesenchymal stem cells," Methods in Molecular Biology, vol. 407, pp. 225-243, 2007.

[46] R. E. Newman, D. Yoo, M. A. LeRoux, and A. DanilkovitchMiagkova, "Treatment of inflammatory diseases with mesenchymal stem cells," Inflammation and Allergy, vol. 8, no. 2, pp. 110-123, 2009.

[47] T. Meyerrose, S. Olson, S. Pontow et al., "Mesenchymal stem cells for the sustained in vivo delivery of bioactive factors," Advanced Drug Delivery Reviews, vol. 62, no. 12, pp. 11671174, 2010.

[48] K. Ksiazek, "A comprehensive review on mesenchymal stem cell growth and senescence," Rejuvenation Research, vol. 12, no. 2, pp. 105-116, 2009.

[49] D. Siniscalco, C. Giordano, U. Galderisi et al., "Intra-brain microinjection of human mesenchymal stem cells decreases allodynia in neuropathic mice," Cellular and Molecular Life Sciences, vol. 67, no. 4, pp. 655-669, 2010.

[50] M. K. Majumdar, M. A. Thiede, J. D. Mosca, M. Moorman, and S. L. Gerson, "Phenotypic and functional comparison of cultures of marrow-derived mesenchymal stem cells (MSCs) and stromal cells," Journal of Cellular Physiology, vol. 176, no. 1, pp. 57-66, 1998.

[51] L. da Silva Meirelles, A. M. Fontes, D. T. Covas, and A. I. Caplan, "Mechanisms involved in the therapeutic properties of mesenchymal stem cells," Cytokine and Growth Factor Reviews, vol. 20, no. 5-6, pp. 419-427, 2009.

[52] M. Giuliani, M. Fleury, A. Vernochet et al., "Long-lasting inhibitory effects of fetal liver mesenchymal stem cells on Tlymphocyte proliferation," PLoS One, vol. 6, no. 5, Article ID e19988, 2011.

[53] M. J. Hoogduijn, F. Popp, R. Verbeek et al., "The immunomodulatory properties of mesenchymal stem cells and their use for immunotherapy," International Immunopharmacology, vol. 10, no. 12, pp. 1496-1500, 2010.

[54] M. D. Nicola, C. Carlo-Stella, M. Magni et al., "Human bone marrow stromal cells suppress T-lymphocyte proliferation induced by cellular or nonspecific mitogenic stimuli," Blood, vol. 99, no. 10, pp. 3838-3843, 2002. 
[55] S. Beyth, Z. Borovsky, D. Mevorach et al., "Human mesenchymal stem cells alter antigen-presenting cell maturation and induce T-cell unresponsiveness," Blood, vol. 105, no. 5, pp. 2214-2219, 2005.

[56] F. Dazzi and F. M. Marelli-Berg, "Mesenchymal stem cells for graft-versus-host disease: close encounters with T cells," European Journal of Immunology, vol. 38, no. 6, pp. 1479-1482, 2008.

[57] P. Ashwood, B. A. Corbett, A. Kantor, H. Schulman, J. Van de Water, and D. G. Amaral, "In search of cellular immunophenotypes in the blood of children with autism," PLoS One, vol. 6, no. 5, Article ID e19299, 2011.

[58] K. Suzuki, H. Matsuzaki, K. Iwata et al., "Plasma cytokine profiles in subjects with high-functioning autism spectrum disorders," PLoS One, vol. 6, no. 5, Article ID e20470, 2011.

[59] S. Gupta, D. Samra, and S. Agrawal, "Adaptive and innate immune responses in autism: rationale for therapeutic use of intravenous immunoglobulin," Journal of Clinical Immunology, vol. 30, supplement 1, pp. S90-S96, 2010.

[60] A. M. Enstrom, C. E. Onore, J. A. Van de Water, and P. Ashwood, "Differential monocyte responses to TLR ligands in children with autism spectrum disorders," Brain, Behavior, and Immunity, vol. 24, no. 1, pp. 64-71, 2010.

[61] A. L. Oblak, D. L. Rosene, T. L. Kemper, M. L. Bauman, and G. J. Blatt, "Altered posterior cingulate cortical cyctoarchitecture, but normal density of neurons and interneurons in the posterior cingulate cortex and fusiform gyrus in autism," Autism Research, vol. 4, pp. 200-211, 2011.

[62] E. R. Whitney, T. L. Kemper, D. L. Rosene, M. L. Bauman, and G. J. Blatt, "Density of cerebellar basket and stellate cells in autism: evidence for a late developmental loss of Purkinje cells," Journal of Neuroscience Research, vol. 87, no. 10, pp. 2245-2254, 2009.

[63] E. Courchesne, C. M. Karns, H. R. Davis et al., "Unusual brain growth patterns in early life in patients with autistic disorder: an MRI study," Neurology, vol. 57, no. 2, pp. 245-254, 2001.

[64] M. L. Bauman and T. L. Kemper, "Neuroanatomic observations of the brain in autism: a review and future directions," International Journal of Developmental Neuroscience, vol. 23, no. 2-3, pp. 183-187, 2005.

[65] D. A. Fortin, T. Srivastava, and T. R. Soderling, "Structural modulation of dendritic spines during synaptic plasticity," Neuroscientist. In press.

[66] A. T. Sørensen, N. Rogelius, C. Lundberg, and M. Kokaia, "Activity-dependent long-term plasticity of afferent synapses on grafted stem/progenitor cell-derived neurons," Experimental Neurology, vol. 229, no. 2, pp. 274-281, 2011.

[67] R. C. Rodrigues Hell, M. M. Silva Costa, A. M. Goes, and A. L. Oliveira, "Local injection of BDNF producing mesenchymal stem cells increases neuronal survival and synaptic stability following ventral root avulsion," Neurobiology of Disease, vol. 33, no. 2, pp. 290-300, 2009.

[68] Y. K. Chang, M. H. Chen, Y. H. Chiang et al., "Mesenchymal stem cell transplantation ameliorates motor function deterioration of spinocerebellar ataxia by rescuing cerebellar Purkinje cells," Journal of Biomedical Science, vol. 18, article 54, no. 1, 2011.

[69] J. Deng, Z. M. Zou, T. L. Zhou et al., "Bone marrow mesenchymal stem cells can be mobilized into peripheral blood by G-CSF in vivo and integrate into traumatically injured cerebral tissue," Neurological Sciences, vol. 32, no. 4, pp. 641-651, 2011.
[70] L. Li and J. Jiang, "Regulatory factors of mesenchymal stem cell migration into injured tissues and their signal transduction mechanisms," Frontier Medical, vol. 5, pp. 33-39, 2011.

[71] D. J. Prockop, C. A. Gregory, and J. L. Spees, "One strategy for cell and gene therapy: harnessing the power of adult stem cells to repair tissues," Proceedings of the National Academy of Sciences of the United States of America, vol. 100, no. 1, pp. 11917-11923, 2003.

[72] A. Augello, T. B. Kurth, and C. De Bari, "Mesenchymal stem cells: a perspective from in vitro cultures to in vivo migration and niches," European Cells and Materials, vol. 20, pp. 121133, 2010.

[73] E. N. Momin, A. Mohyeldin, H. A. Zaidi, G. Vela, and A. Quiñones-Hinojosa, "Mesenchymal stem cells: new approaches for the treatment of neurological diseases," Current Stem Cell Research and Therapy, vol. 5, no. 4, pp. 326-344, 2010. 

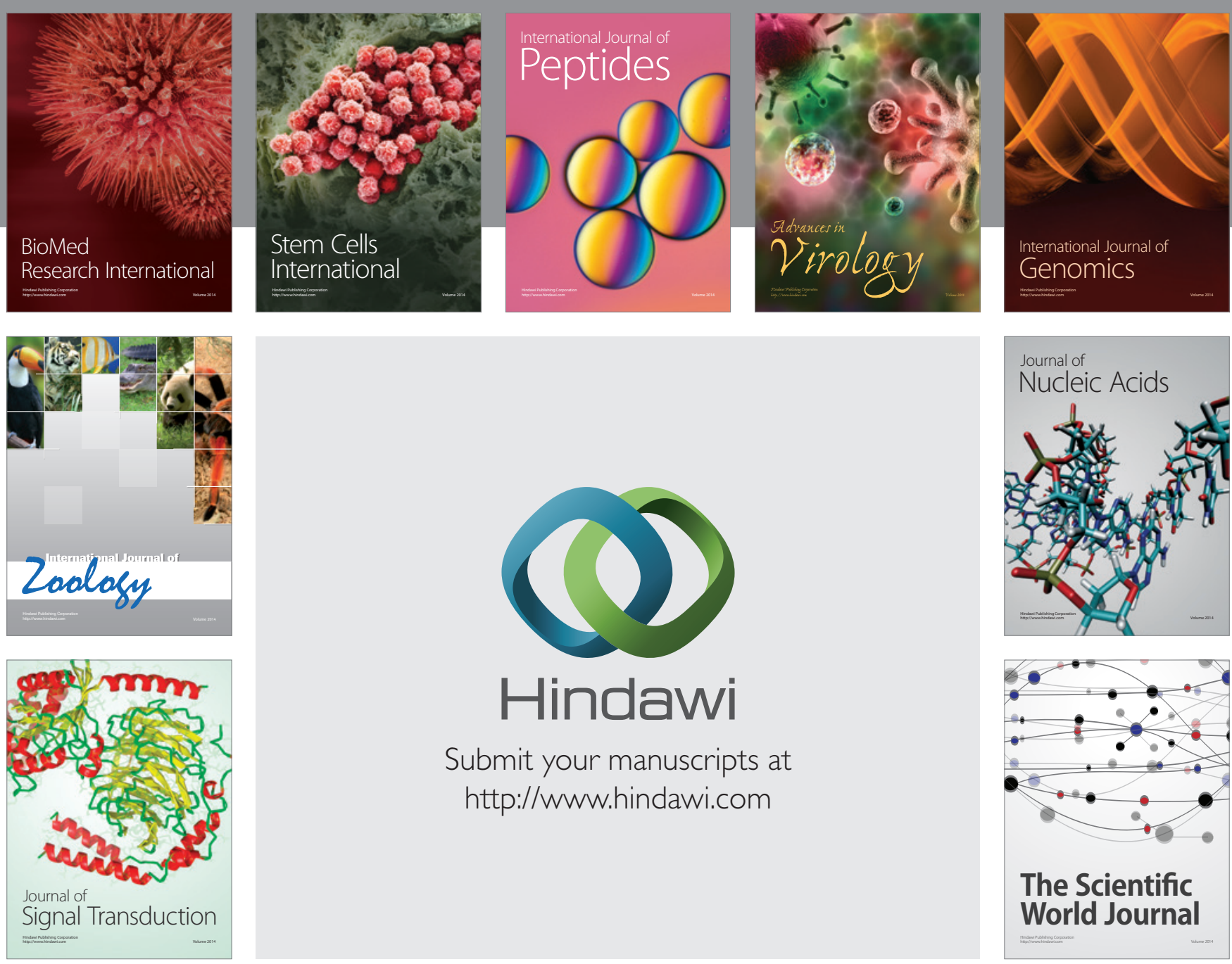

Submit your manuscripts at

http://www.hindawi.com
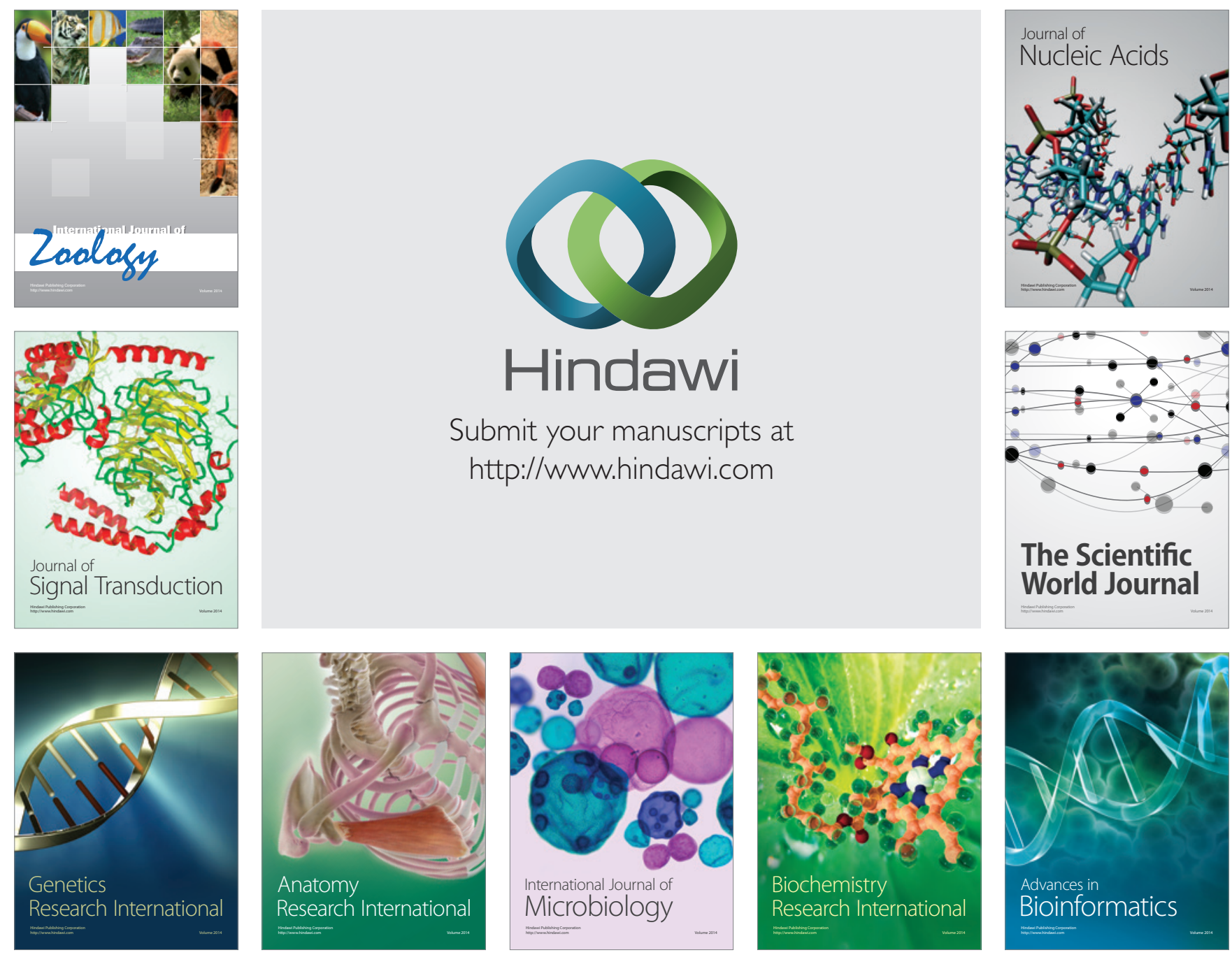

The Scientific World Journal
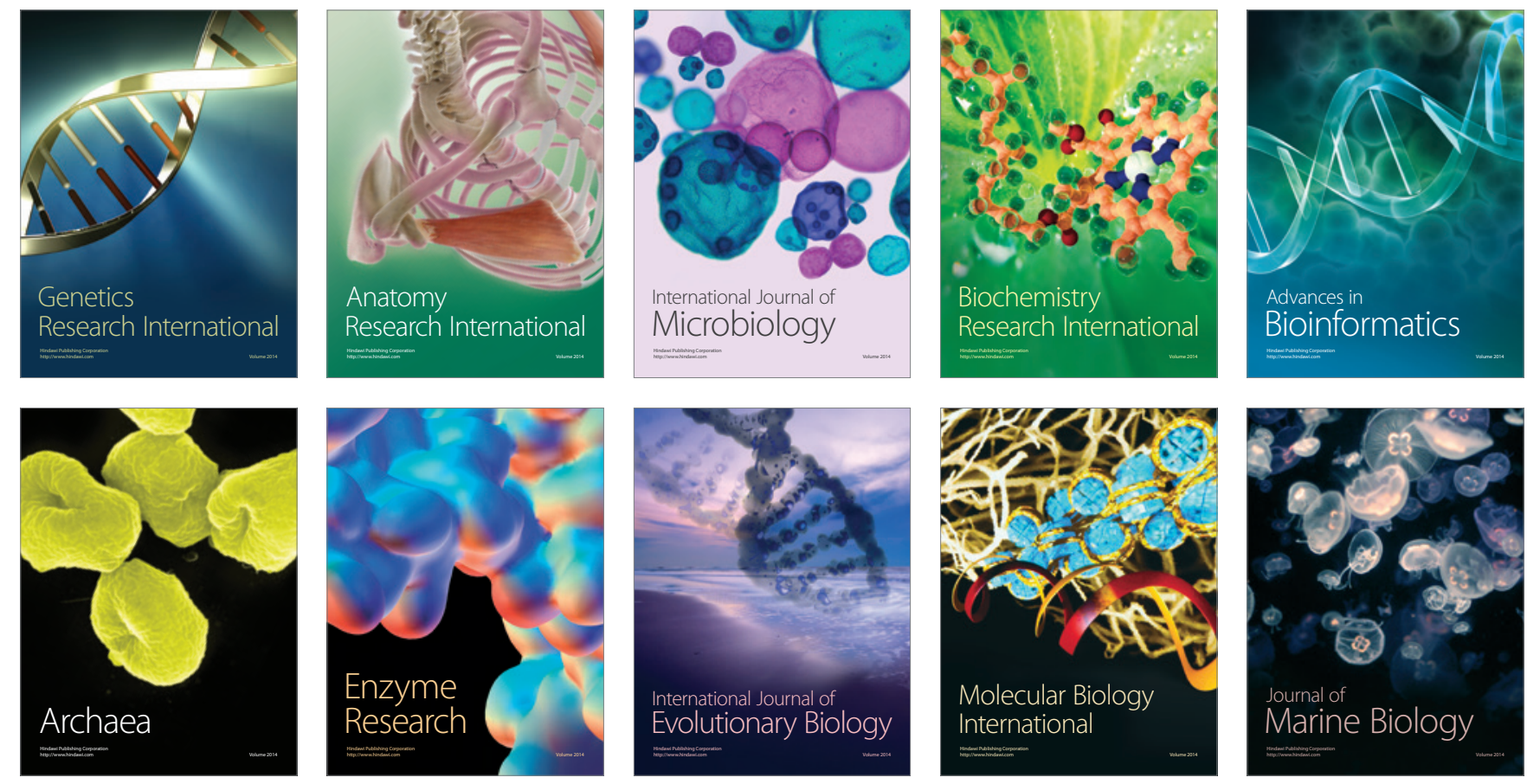